\title{
Financial burden for tuberculosis patients in low- and middle-income countries: a systematic review
}

\author{
Tadayuki Tanimura, Ernesto Jaramillo, Diana Weil, Mario Raviglione and \\ Knut Lönnroth
}

\section{Affiliation:}

Global TB Programme, World Health Organization, Geneva, Switzerland.

\section{Correspondence:}

K. Lönnroth, Global TB Programme, World Health Organization, 20 Avenue Appia, CH-1211 Geneva 27, Switzerland.

E-mail: lonnrothkawho.int

ABSTRACT In order to inform the development of appropriate strategies to improve financial risk protection, we conducted a systematic literature review of the financial burden of tuberculosis (TB) faced by patients and affected families.

The mean total costs ranged from $\$ 55$ to $\$ 8198$, with an unweighted average of $\$ 847$. On average, $20 \%$ (range $0-62 \%)$ of the total cost was due to direct medical costs, 20\% (0-84\%) to direct non-medical costs, and $60 \%(16-94 \%)$ to income loss. Half of the total cost was incurred before TB treatment. On average, the total cost was equivalent to $58 \%$ (range 5-306\%) of reported annual individual and 39\% (4-148\%) of reported household income. Cost as percentage of income was particularly high among poor people and those with multidrug-resistant TB. Commonly reported coping mechanisms included taking a loan and selling household items.

The total cost of TB for patients can be catastrophic. Income loss often constitutes the largest financial risk for patients. Apart from ensuring that healthcare services are fairly financed and delivered in a way that minimises direct and indirect costs, there is a need to ensure that TB patients and affected families receive appropriate income replacement and other social protection interventions.

@ERSpublications

Costs and income loss put people with $\mathrm{TB}$ at financial risk, requiring mitigation with social protection interventions http://ow.ly/sqgRU

For editorial comments see page 1563.

Received: Nov 072013 | Accepted after revision: Dec 142013 | First published online: Feb 132014

Support statement: This study was funded by the World Health Organization.

Conflict of interest: None declared.

ERJ Open articles are open access and distributed under the terms of the Creative Commons Attribution NonCommercial Licence 3.0. This article is one of a small annual allocation selected for open access publication at the discretion of the editor. 


\section{Introduction}

An estimated 100 million people fall below the poverty line each year because of the financial burden of disease [1]. Tuberculosis (TB), which mostly affects the poorest of the poor, is an example of a disease that can substantially contribute to the disease poverty trap $[2,3]$.

Most countries aim to provide TB diagnosis and treatment free of charge within public health services. Access to free TB care has expanded substantially over the past two decades through national efforts and global financial support [4]. However, many TB patients and families are still facing very high direct and indirect costs due to TB illness and care-seeking, hampering access and putting people at risk of financial ruin or further impoverishment $[5,6]$.

The World Health Organization (WHO) is developing a post-2015 Global TB Strategy, which highlights the need for all countries to progress towards universal health coverage to ensure "universal access to needed health services without financial hardship in paying for them," [7] as well as social protection mechanisms for "income replacement and social support in the event of illness" [8,9]. One of the tentative global targets for the strategy is "no TB-affected family facing catastrophic costs due to TB", to be reached globally by 2020 [10]. This target reflects the anticipated combined financial risk protection effect of the progressive realisation of both universal health coverage and social protection.

Universal health coverage has long been on the global TB control agenda, which stresses the need for universally accessible, affordable and patient-centred services [2, 11-13]. Social protection has emerged more recently as a key policy area for TB care and prevention [10, 14-17]. Social protection involves schemes to cover costs beyond direct medical costs, including compensation of lost income. Examples of social protection schemes include sickness insurance, disability grants, other conditional or unconditional cash transfers, food assistance, travel vouchers and other support packages [14]. Such schemes exist in most countries, but may not be fully implemented due to inadequate financing or insufficient capacities of the healthcare and social welfare systems [18]. Furthermore, they may not include TB patients among those eligible $[10,14,17]$.

In order to inform the development of appropriate strategies for improved access and financial risk protection for people with $\mathrm{TB}$, we have undertaken a systematic literature review on medical costs, nonmedical costs, as well as income loss for TB patients and affected households in different settings, as well as the main drivers of those costs.

\section{Methods}

Eligibility criteria

This review includes studies written in English, conducted in low- and middle-income countries and published from inception to March 31, 2013, reporting data on medical costs, non-medical costs and/or income loss incurred by TB patients during the process of seeking and receiving care for TB, as well as coping strategies. We excluded studies in which only total cost was reported without any disaggregation into direct and indirect costs and studies using secondary data derived from other published articles.

\section{Information sources and search strategies}

We searched the following electronic databases: PubMed; Global Information Full Text; Index Medicus for Africa, South-East Asia, Eastern Mediterranean region, and Western Pacific region; and Literatura Latinoamericana y del Caribe en Ciencias de la Salud. Furthermore, we checked reference lists of reviewed studies [19-22] and of documents and meeting reports from the World Bank and WHO websites. The search terms were "tuberculosis" (tuberculosis, TB, or tuberculosis as a MeSH Term in PubMed) and “cost" ( $\operatorname{cost}(\mathrm{s})$, expense(s), economic, expenditure(s), payment(s), out-of-pocket, financial, impoverishment, or catastrophic).

\section{Data extraction}

We extracted the following background information: country, location, urban/rural, year of the publication and data collection, setting characteristics, and method of data collection and calculation of costs and income loss.

We stratified, to the extent data allowed, into the following cost components: direct medical costs (consultations, tests, medicines and hospitalisation, etc.), direct non-medical cost (transport and food during healthcare visits, etc.) and indirect costs (lost income). If possible, cost was stratified by socioeconomic status, hospitalisation/ambulatory treatment, drug-resistant TB or drug-susceptible TB, and sex.

The cost components were extracted separately for the pre- and post-TB diagnosis period, if available. Pre$\mathrm{TB}$ treatment costs are those incurred between the onset of symptoms and the initiation of treatment for 
TB. In all studies, this data was collected retrospectively at a point in time after diagnosis. Post-diagnostic costs are those incurred from TB diagnosis to completion of treatment. Costs during treatment were either collected prospectively through repeat surveys of patients in treatment or retrospectively. If retrospectively collected at some point during treatment, the cost was then extrapolated to the planned treatment duration in most studies.

We also extracted data on costs as a percentage of reported individual and/or household income, if available. For all studies done in countries for which both "gross average nominal monthly wage" in the International Labour Organization's global wage database [23] and "income share held by lowest 20\%" in the World Bank's online data [24] were available, we also computed total costs as percentage of average annual income and percentage of annual income in the lowest quintile for each respective country. The latter was done under the assumption that TB mostly affects the poorest quintile in any given setting. We used the available data for the nearest year to a year of the data collection.

Where available, we extracted information about mechanisms for coping with financial burden, such as taking a loan or selling property.

\section{Summary measures and synthesis of results}

The focus of the analysis was on the distribution of the magnitude and components of costs across settings. We also report descriptive analyses of the central tendencies of the data. For each variable we provide the range of reported means across studies, unweighted average of means (with standard deviation), and the median and interquartile range of means. When a mean value for all study subjects in a given study was not available, we re-calculated an unweighted mean across subgroup within the study. We also report the range and unweighted average of percentage distributions of different cost components. Under the assumption of large heterogeneity, we decided a priori to focus the analysis on the variations across studies, while providing summary estimates for some variables as an indication of central tendencies across studies. We opted not to calculate confidence intervals for the unweighted average of means, in order to avoid a false impression of precision for the measures of central tendency.

If one study reported data from several different country surveys, each survey was analysed as a separate observation. Data availability for variables of interest varied across studies. Summary statistics are therefore based on different number of studies. Mean cost values were available from 44 studies (reporting 47 surveys) of the 49 studies (reporting 52 surveys). Only median values were reported in five studies. We therefore did not use median values for summarising the key variables across studies. However, where applicable, median values were used for comparison of different subgroups within studies.

Costs in international dollars (\$) were calculated by multiplying raw cost data in US dollars, the exchange rate with the local currency for the year of data collection and the cumulative inflation rate [25] from the year of data collection to 2010 (latest year of data availability), and divided it by the purchasing power parities conversion factor [26]. The exchange rates reported in reviewed articles were preferentially used for the calculation and, in the absence of them, we used the exchange rates from the "National Accounts Main Aggregates Database" of the United Nations Statistics Division [27] and the exchange rate of Sudan from UN data [28] as the data of Sudan in a studied year is missing in the former source.

\section{Results}

49 studies fulfilled the inclusion criteria (fig. 1). One study without cost data was included since it provided data on coping strategies [29]. Details about included studies are provided in table 1.

Mean total costs ranged from $\$ 55$ to $\$ 8198$ across 40 surveys for which mean costs and conversion values were available, with an unweighted average of $\$ 847$, and a median of $\$ 379$. The proportion of direct medical costs out of total cost ranged from 0-62\% (unweighted average 20\%) across the 25 surveys that provided disaggregated data on direct medical, direct non-medical, and indirect costs. Direct non-medical costs ranged from 0-84\% (unweighted average 20\%) and indirect costs (income loss) from 16-94\% (unweighted average $60 \%$ ) of total cost (table 2).

Eight studies fully disaggregated direct and indirect costs both before and during treatment. On average, costs incurred before TB treatment was initiated represented $50 \%$ of the total cost (fig. 2). While indirect costs dominated both before and during treatment, direct costs were relatively more important before than during treatment. Direct costs were driven mostly by medical costs before treatment and by non-medical costs during treatment.

Across 18 studies that further disaggregated direct medical costs, the proportion of drug costs out of direct medical costs ranged from $0 \%$ to $86 \%$ (unweighted average of $34 \%$ ), while the contribution from diagnostic 


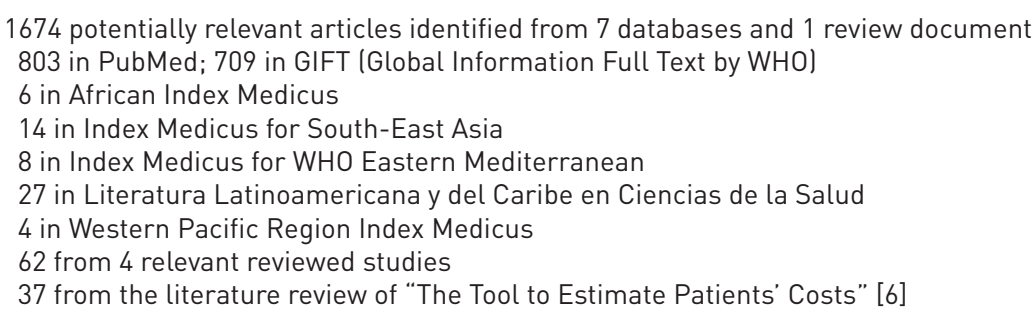

37 from the literature review of "The Tool to Estimate Patients" Costs" [6]

1674 Evaluation of title/abstract/figures

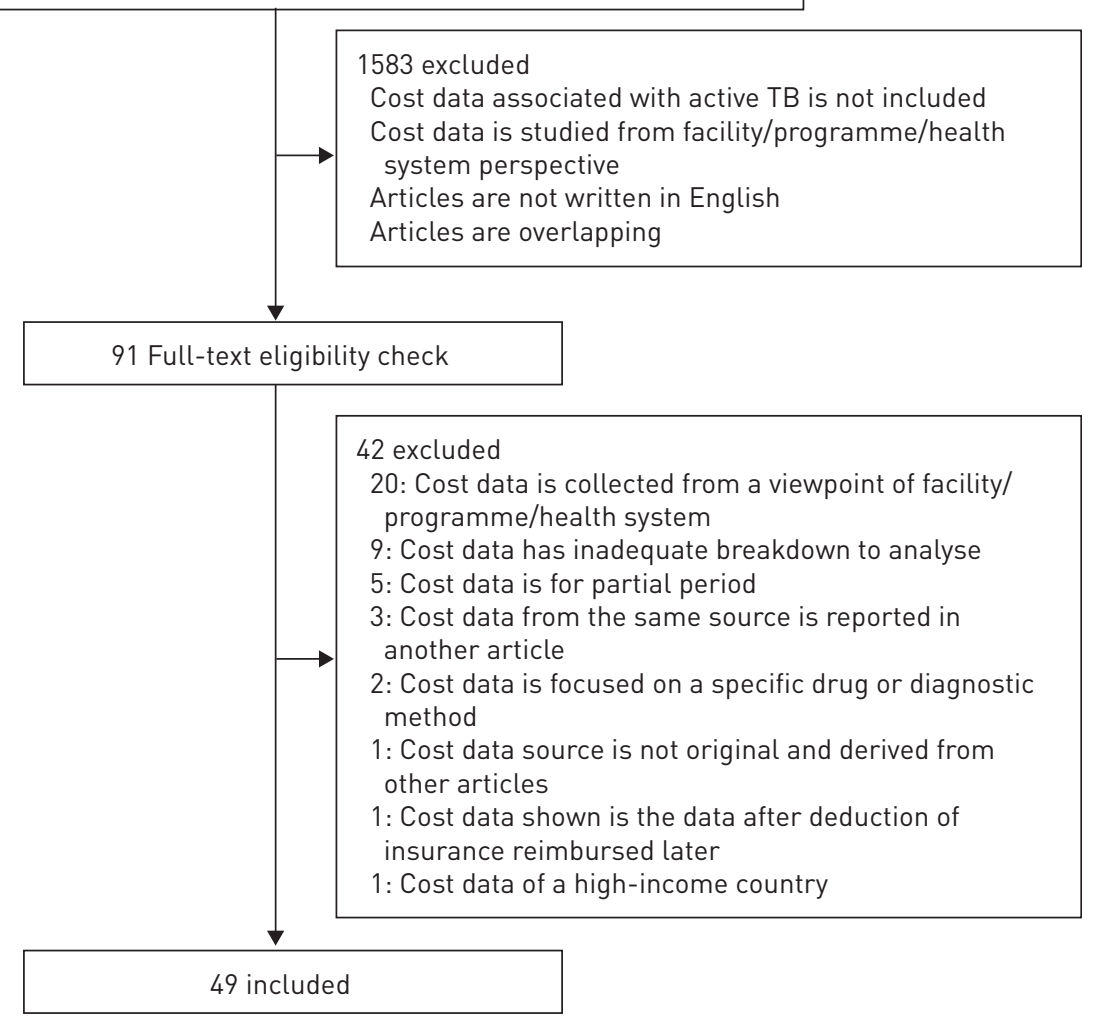

FIGURE 1 Flow chart of literature search.

and follow-up test costs ranged from $0 \%$ to $94 \%$ (unweighted average of $27 \%$,) and hospitalisation costs from $0 \%$ to $71 \%$ (unweighted average of $24 \%$ ).

Transport costs (range 11-96\%, unweighted average 50\%), and food costs (range 0-89\%, unweighted average $37 \%$,) were the largest contributors to direct non-medical costs in 16 studies that disaggregated the direct non-medical costs.

There was a large variation across studies in the mean total cost as percentage of income, with skewed distributions due to a few studies reporting very high costs (table 3 and fig. 3). Total cost as percentage of reported annual individual income ranged from $5 \%$ to $306 \%$ (unweighted average 58\%, median $44 \%$ ), while the total cost as percentage of reported household income ranged from $4 \%$ to $148 \%$ (unweighted average $39 \%$, median $23 \%$ ). Total cost as percentage of the average annual income in the lowest income quintile of the country of study ranged from 3\% to 578\% (unweighted average 89\%, median 21\%).

In 12 studies that disaggregated data by socioeconomic status group, there was no consistent tendency of difference in the absolute total cost incurred. However, the five studies that reported the cost as percentage of the reported income specific to each group found that the cost was considerably higher among the lower socioeconomic status groups [30, 34, 38, 40, 46]. 


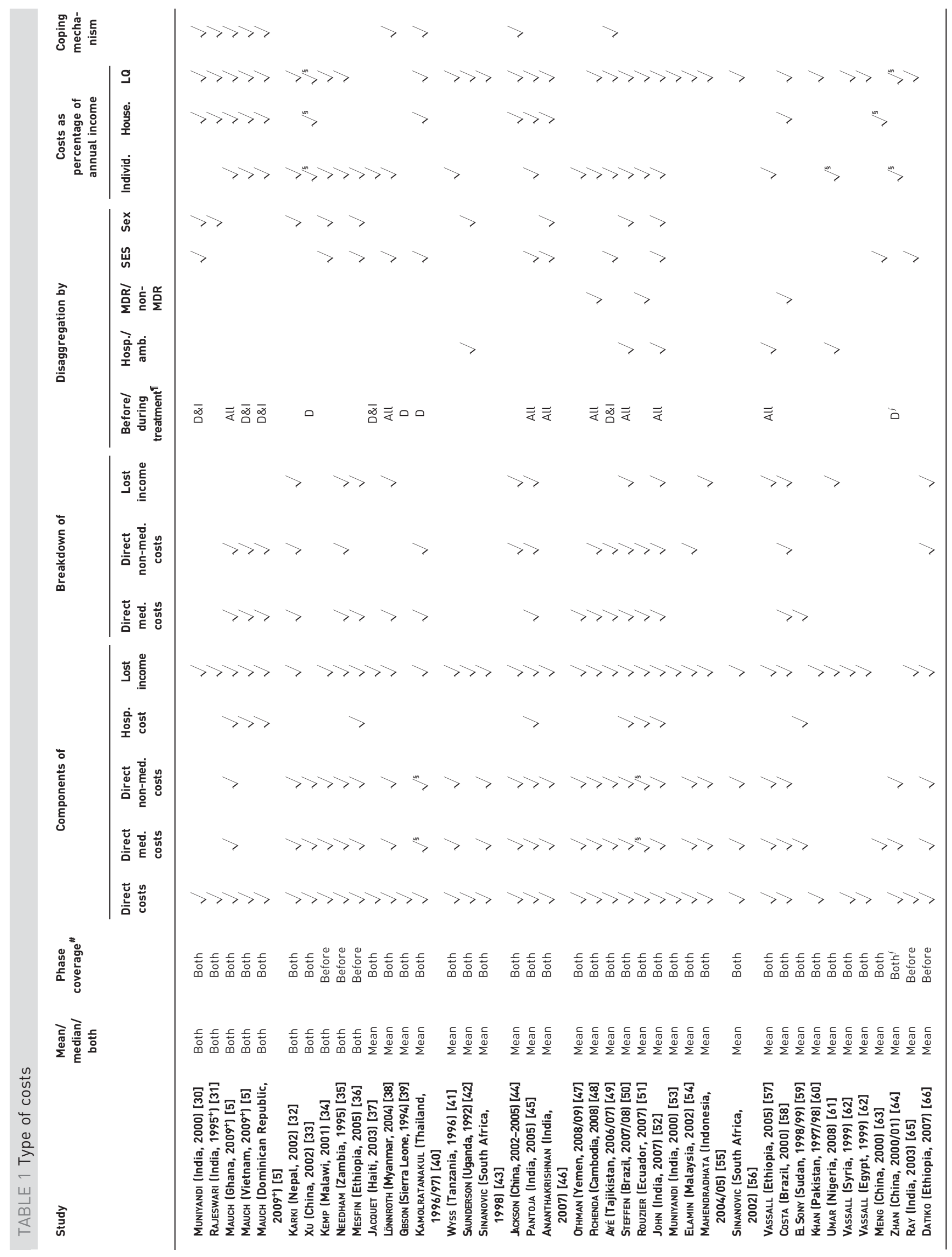




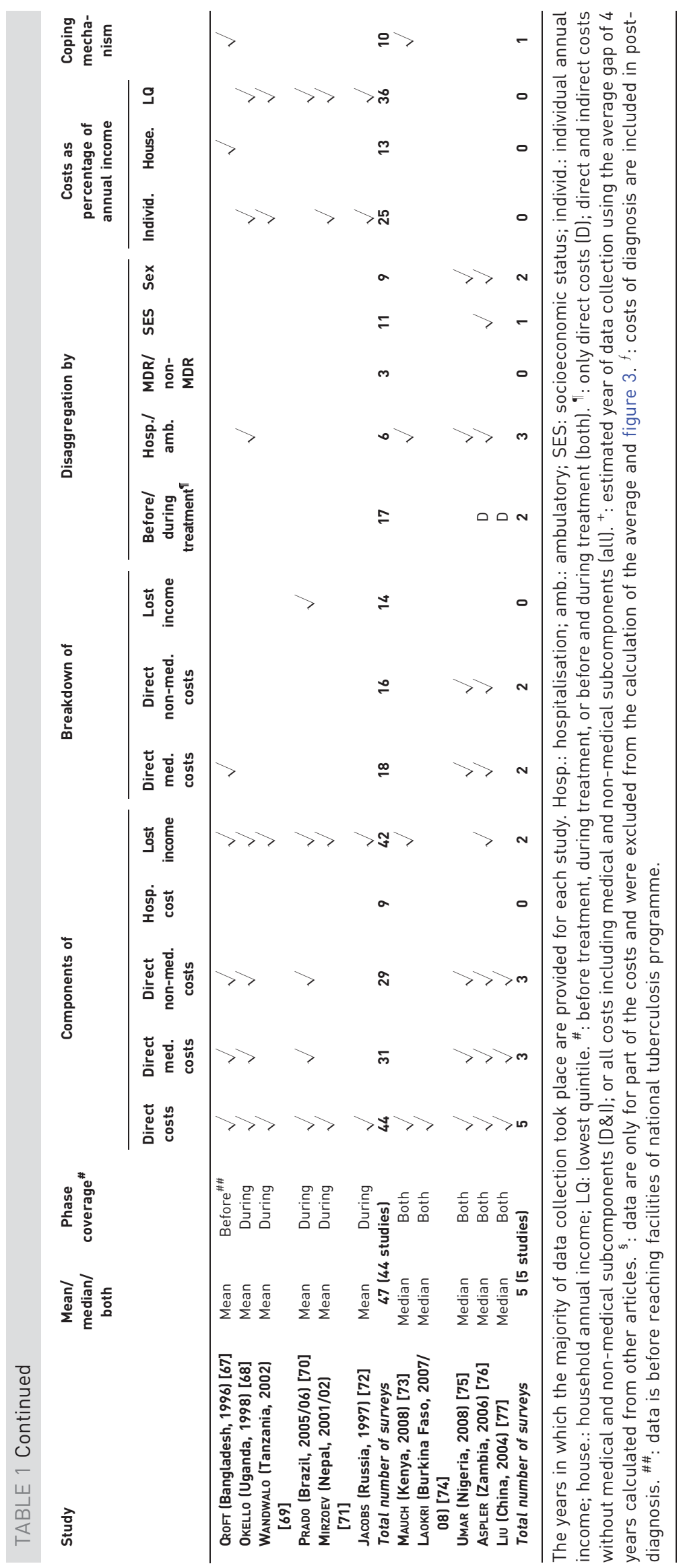


TABLE 2 Patient costs and distribution of costs from 25 surveys with disaggregated medical direct costs, non-medical direct costs and income loss

Cost category

Non-medical costs

\section{Unweighted average of mean costs \$ (SD) (range)}

Median (IQR) of mean costs \$

Unweighted average contribution \% (range)
Direct costs

Medical costs
Indirect costs

Total costs

IQR: interquartile range. Costs are quoted in international dollars.

Among the three studies that disaggregated the total cost for patients with multidrug-resistant (MDR)-TB versus drug-susceptible $\mathrm{TB}$, the cost was considerably higher for MDR-TB patients (fig. 3). The difference in indirect costs was larger than that of the direct costs in two studies $[48,51]$. The total costs as percentage of reported individual income for MDR-TB patients and drug-susceptible TB patients in two of the three studies were 223\% (\$14388) versus 31\% (\$2008) in Ecuador [51] and 76\% (\$2953) versus 24\% (\$923) in Cambodia [48]. For the third study, from Brazil, that calculated income loss based on reported income after TB diagnosis, the cost burden was similar for MDR-TB and drug-susceptible patients (34\% versus $27 \%$ of reported annual income) [58].

In 11 studies that disaggregated the total costs between males and females there was no consistent tendency of difference in absolute total costs. However, in two studies in Nigeria and Zambia that also reported individual income by sex, the costs for females as percentage of reported income were significantly larger $[75,76]$.

Commonly reported coping mechanisms included taking a loan, selling household items, using savings, and transfers from relatives (table 4). The amounts were not reported.

FIGURE 2 Breakdown of direct and indirect costs before and during treatment (eight studies). Percentages are proportion of respective sub-component cost out of the total cost.

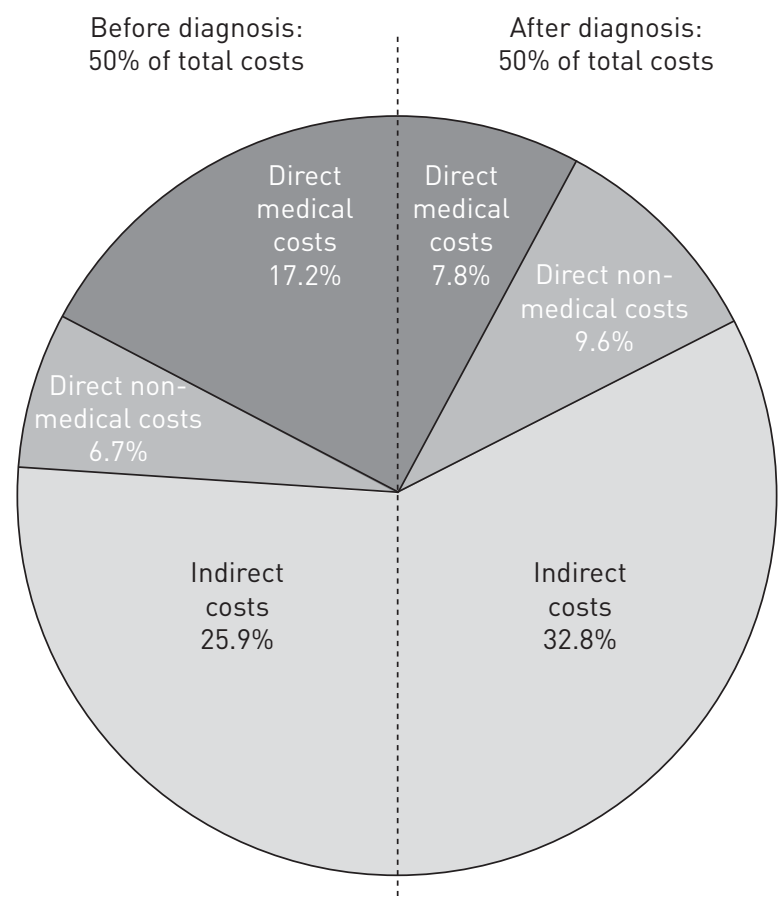


TABLE 3 Costs as percentage of annual income

\section{Surveys $n$}

Direct

costs \%
Lost income

$\%$
Total costs

$\%$
Range of total costs $\%$

\section{Individual}

\begin{tabular}{|c|c|c|c|c|c|c|}
\hline \multirow[t]{2}{*}{ Reported income } & 22 & Average of mean (SD) & 21 (27) & $37(43)$ & $58(64)$ & $5-306$ \\
\hline & & Median of mean (IQR) & $10(5-23)$ & $24(12-37)$ & $44(15-75)$ & \\
\hline \multirow[t]{2}{*}{ Annual wage } & 35 & Average of mean (SD) & $9(14)$ & $21(29)$ & $30(42)$ & $0-211$ \\
\hline & & Median of mean (IQR) & $3(2-12)$ & $4(2-30)$ & $7(4-41)$ & \\
\hline \multirow[t]{2}{*}{ Wage of lowest $20 \%$} & 34 & Average of mean (SD) & $25(42)$ & 64 (102) & 89 (139) & $3-578$ \\
\hline & & Median of mean (IQR) & $8(4-29)$ & $14(6-88)$ & $21(10-101)$ & \\
\hline \multirow[t]{2}{*}{ Reported household income } & 7 & Average of mean (SD) & $16(17)$ & $22(29)$ & $39(46)$ & $4-148$ \\
\hline & & Median of mean (IQR) & $11(9-15)$ & $14(4-20)$ & $23(14-36)$ & \\
\hline
\end{tabular}

IQR: interquartile range.

\section{Discussion}

This review demonstrates that the economic burden of seeking TB care is often very high for patients and affected households. Clearly, accessing TB care and continuing treatment comes with a high risk of financial ruin or further impoverishment for many people. In most settings, income loss is a dominating reason for the high costs.

However, the financial burden varies considerably both between individuals in the same setting and between settings. This should be expected as the burden is determined by a range of factors, such as socioeconomic status, clinical needs, health system structure, TB service delivery model, distance to health services, insurance coverage, capacity to work, existence of any social protection scheme, and effectiveness of informal social networks supporting patients and families.

This review shows that, while costs are catastrophic for many patients, they are minimal for others. It is crucial to identify the factors that contribute to costs incurred and to financial ruin. Unfortunately, few studies provided sufficient details about the models and context of care to allow us to quantify the relative importance of the different factors. However, the available data hint at some key explanations and intervention entry points.

Cost of medicines and diagnostic tests were important drivers of direct medical costs, despite TB medicines and basic TB-specific tests being free of charge in services linked to the national TB programme in most countries. Detailed accounts of which medicines and tests were accessed were not available from any of the studies, but authors of some studies speculated about several possible reasons for cost incurred: patients may not have been offered free medicines for drug-resistant TB; some patients pay for services outside national TB programme facilities, e.g. in the private sector; and costs of adjuvant medicines may have contributed. Hospitalisation was another key driver of direct costs. In some settings, patients are routinely hospitalised, especially if MDR-TB is diagnosed. The necessity of some medical procedures and routine hospitalisation is not substantiated. Ensuring use of evidence-based cost-effective diagnostic and treatment routines can reduce direct medical costs $[49,52]$. The costs of appropriate services, within national programmes as well as outside, should be fully subsidised given the public health implications of failure to ensure access and use of quality TB care, the known low socioeconomic status of most TB patients, and recommended prioritisation of coverage of priority health interventions like for TB under universal health coverage objectives [78]. Ensuring provision of free-of-charge TB diagnosis and treatment also in private facilities have been shown to reduce the direct costs for patients $[45,79]$.

Transport and food costs accounted for a major part of direct non-medical costs for patients. Provision of transport vouchers, reimbursement schemes and food assistance could be used to reduce or compensate for such costs. Furthermore, decentralisation of patient supervision (including directly observed therapy), e.g. through community-based [43,66] or workplace-based treatment [43], can reduce transport costs as well as income loss for patients.

Minimising costs during treatment does not guarantee financial risk protection since a large part of the cost is often incurred before treatment starts. In addition, costs during the first 2 months of treatment tend to dominate the costs incurred during treatment [29, 57, 74]. Peaking costs around the time of diagnosis and treatment initiation may constitute one of the most powerful barriers for people ill with TB to complete the 

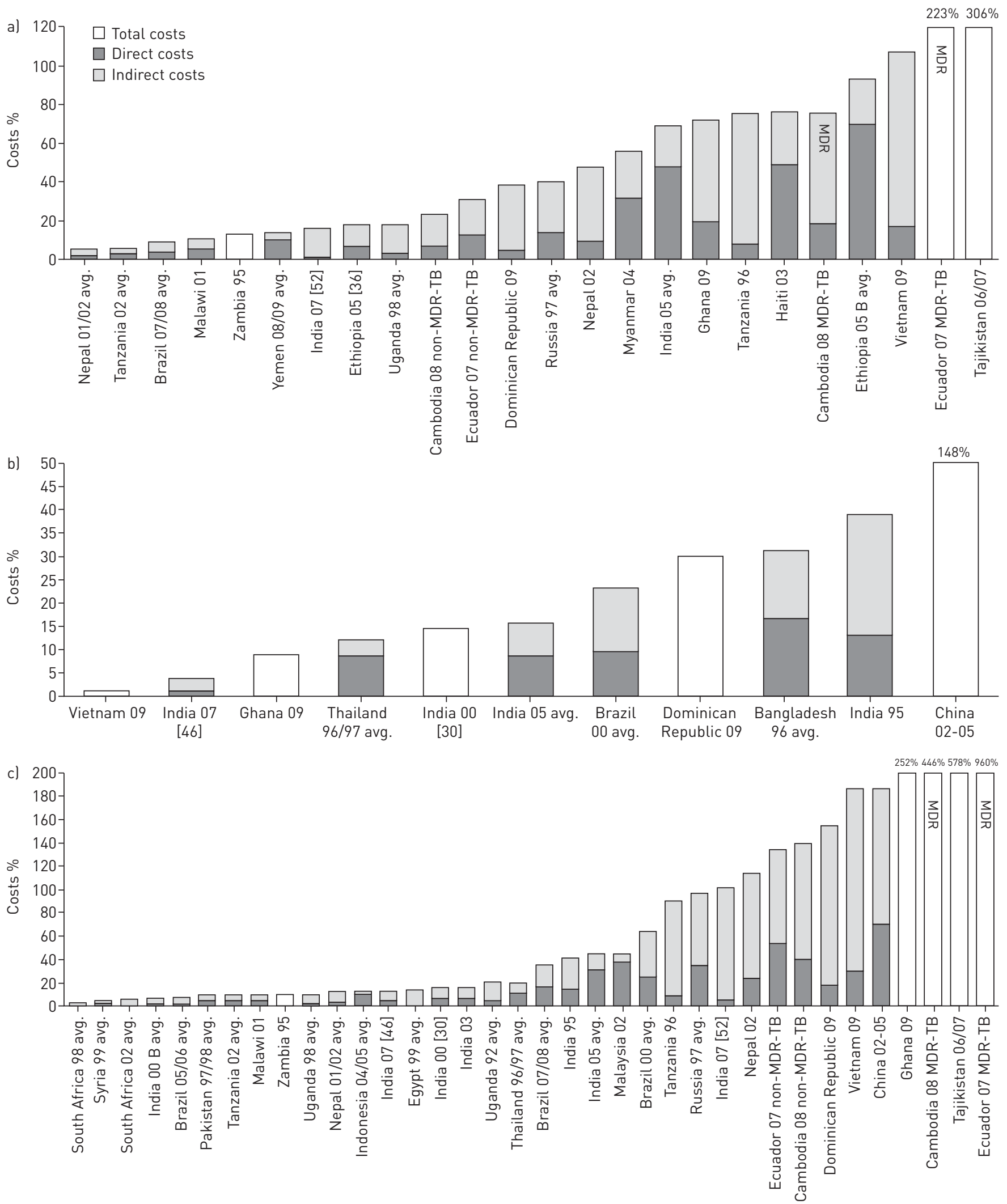

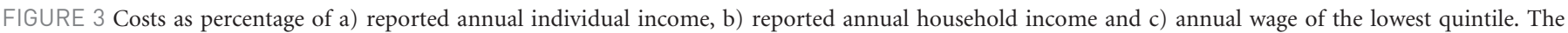

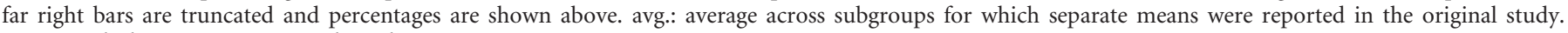
MDR: multidrug resistant; TB: tuberculosis. 
TABLE 4 Percentage of patients pursuing specific coping strategies

Country, area, year of data collection
Taking loan $\%$
Selling household

items \%
Using own

savings $\%$
Transfers from

relatives \%

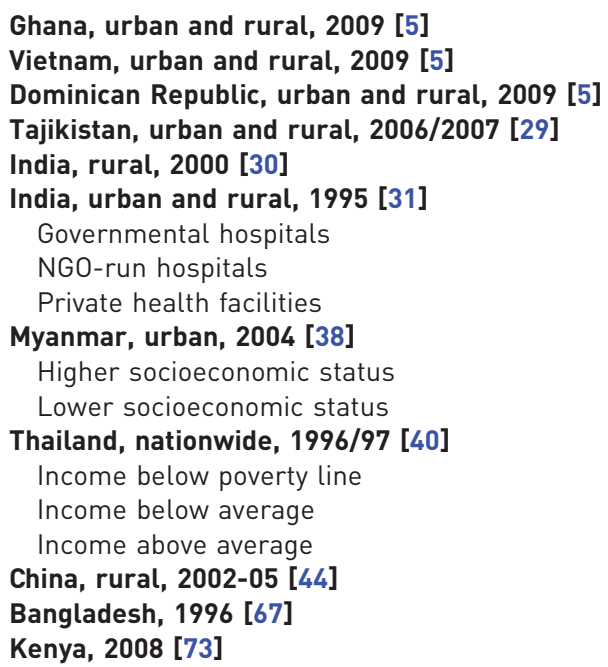

NGO: nongovernment organisation.

diagnostic search, to start treatment once diagnosed, and to adhering to treatment to cure. Therefore, effective intervention at the time of diagnosis and treatment initiation may have significant impact.

Affordable health services, as well as social protection schemes, are needed to enable access, reduce delays and to compensate for direct and indirect costs. Social protection schemes cover general categories of vulnerable persons, such as those with disabilities or sickness or other causes of limited or reduced income. TB patients may in some settings meet criteria for such support. In other settings, TB-specific targeting may be in place for provision of specific packages of social support such as food stuffs or cash transfers, with or without means testing. This review identified two groups of TB patients that require special attention: people with MDR-TB and people in the lowest income brackets. For the first group, the debilitating nature of the disease, its long-term care, and associated income loss may put them at special risk for catastrophic costs. For the second group, low-income means that the relative costs of direct medical care and non-medical costs, as well as income loss due to precarious informal employment in many cases, may exacerbate already serious economic vulnerability and catastrophic costs may carry relatively greater impact.

This study has several limitations. First, there may be both publication and selection bias that could limit the representativeness of the findings. All studies included only people who have been diagnosed with TB. Costs for those ill with TB who seek care but never get diagnosed may be very different, and could for example be dominated by progressing income loss due to untreated illness. Furthermore, most of the studies only included persons diagnosed and started on treatment within national TB programmes. Many people are treated in the private sector. Direct costs are often higher in the private sector than in facilities linked to the national programme $[31,55]$. There is thus a bias towards surveys of public sector patients. Furthermore, there is inclusion bias with regards to some publication languages. Finally, the search strategy was not optimal for the inclusion of studies that only reported on copying mechanism.

Secondly, there were large variations in how data were collected analysed and reported. In particular, the methods for calculating the income loss varied considerably. To accurately measure income loss is more difficult than to measure direct costs [80]. We could not find any clear patterns of methods used which affected cost estimations, except that the indirect costs in studies using reported income after diagnosis was lower than in other studies $[58,73]$. Additional research is needed to validate different measurement approaches.

Thirdly, the studies provided limited information about the health system context. This review provides a cross-sectional snapshot of the financial burden of TB across very different settings. The relevant drivers of costs and interventions to minimise costs will have to be determined locally, based on further local operational research. There is a "TB patient-cost toolkit" available to guide the design of local surveys [6]. 
Fourthly, while studies reported mean values (and median to a lesser extent), no study reported the full distribution of costs, the costs as a percentage of income, or the percentage of patients that had faced "catastrophic costs". However, several possible definitions of "catastrophic costs" were discussed in the reviewed papers, including " $>10 \%$ of monthly household income" [52], " $>10 \%$ of annual household income" [61, 74]; " $>40 \%$ of non-subsistence household income" [5, 44]; or "using non-reversible coping strategies" [29].

The WHO has proposed that "catastrophic health expenditure" be defined as direct healthcare expenditures corresponding to $>40 \%$ of annual discretionary income (income after basic needs, such as food and housing) [7]. The World Bank has proposed a similar definition but has not specified a cut-off value [81]. Indirect costs of care and income loss are not included in these measures. The WHO's Global TB Programme is considering development of TB-specific indicators and target for reduction in catastrophic costs due to TB for patients and their families [10]. Here, all care-related expenditures, as well as income loss, are being considered as relevant elements of overall catastrophic costs. A threshold for TB-related "catastrophic costs" needs to be defined. One possible option would be to adopt the definition of "total costs corresponding to $>10 \%$ of annual household income", which has been proposed by RANSON [82] as appropriate for measuring catastrophic total costs. Incidence of impoverishment may also be considered. Another option is to use generic or locally defined irreversible coping strategies as proxy indicators for catastrophic costs. Further work is needed to assess the correlation between high total cost in relation to income and seemingly irreversible coping strategies.

\section{Acknowledgements}

All authors are staff members of the World Health Organization; the authors alone are responsible for the views expressed in this publication and they do not necessarily represent the decisions or policies of the WHO.

\section{References}

WHO. World Health Statistics 2012. Geneva, World Health Organization, 2012.

2 WHO. Addressing Poverty in TB Control. Options for National TB Control Programmes. Geneva, World Health Organization, 2005.

3 Bates I, Fenton C, Gruber J, et al. Vulnerability to malaria, tuberculosis, and HIV/AIDS infection and disease. Part 1: determinants operating at individual and household level. Lancet Infect Dis 2004; 4: 267-277.

WHO. Global TB. Report 2013. Geneva, World Health Organization, 2013.

Mauch V, Bonsu F, Gyapong M, et al. Free tuberculosis diagnosis and treatment are not enough: patient cost evidence from three continents. Int J Tuberc Lung Dis 2013; 17: 381-387.

6 KNCV Tuberculosis Foundation, WHO, the Japan Anti-Tuberculosis Association. The Tool to Estimate Patients' Costs. Tuberculosis Coalition for Technical Assistance, US Agency for International Development, 2009.

7 WHO. World Health Report 2010: Health Systems Financing - the Path to Universal Coverage. Geneva, World Health Organization, 2010.

8 A Joint Crisis Initiative of the UN Chief Executives Board for Co-ordination on the Social Protection Floor. Geneva, The Social Protection Floor, 2009.

9 International Labour Office. World Social Security Report 2010/11: Providing Coverage in Times of Crisis and Beyond. Geneva, International Labour Organization, 2010.

10 WHO. Eliminating the Catastrophic Economic Burden of TB: Universal Health Coverage and Social Protection Opportunities. Meeting Report from a World Health Organization Consultation to Inform the Post-2015 Global TB Strategy. Geneva, World Health Organization, 2013.

11 WHO. What is Universal Coverage? www.who.int/features/qa/universal_health_coverage/en/index.html Date last updated: October 2012. Date accessed: September 2013.

12 WHO. Contributing to Health System Strengthening - Guiding Principles for National Tuberculosis Programmes. Geneva, World Health Organization, 2008.

13 WHO. The Stop TB Strategy. Geneva, World Health Organization, 2006.

14 Chatham House. Social Protection Interventions for Tuberculosis Control: The Impact, the Challenges, and the Way Forward. London, Chatham House, 2012.

15 Lönnroth K, Jaramillo E, Williams BG, et al. Drivers of tuberculosis epidemics: the role of risk factors and social determinants. Soc Sci Med 2009; 68: 2240-2246.

16 Lönnroth K, Castro KG, Chakaya JM, et al. Tuberculosis control and elimination 2010-50: cure, care, and social development. Lancet 2010; 375: 1814-1829.

17 Hargreaves JR, Boccia D, Evans CA, et al. The social determinants of tuberculosis: from evidence to action. Am J Public Health 2011; 101: 654-662.

18 UNCDF, UNDP. Local Government and Social Protection: Making Service Delivery Available for the Most Vulnerable. UN Capital Development Fund and United Nations Development Programme, 2011.

19 Long Q, Smith H, Zhang T, et al. Patient medical costs for tuberculosis treatment and impact on adherence in China: a systematic review. BMC Public Health 2011; 11: 393.

20 Barter DM, Agboola SO, Murray MB, et al. Tuberculosis and poverty: the contribution of patient costs in subSaharan Africa - a systematic review. BMC Public Health 2012; 12: 980.

21 Ukwaja KN, Modebe O, Igwenyi C, et al. The economic burden of tuberculosis care for patients and households in Africa: a systematic review. Int J Tuberc Lung Dis 2012; 16: 733-739.

22 Fitzpatrick C, Floyd K. A systematic review of the cost and cost effectiveness of treatment for multidrug-resistant tuberculosis. Pharmacoeconomics 2012; 30: 63-80. 
International Labour Organization. Gross Average Nominal Monthly Wage in ILO Global Wage Database. www. ilo.org/travail/info/db/lang--en/index.htm Date accessed: July 2013.

24 World Bank. Income Share Held by Lowest 20\% in the World Bank Database. http://data.worldbank.org/indicator/ SI.DST.FRST.20/countries Date accessed: June 2013.

25 World Bank. Inflation, Consumer Prices (Annual \%) in the World Bank Database. http://data.worldbank.org/ indicator/FP.CPI.TOTL.ZG Date accessed: July 2013.

26 UN. Purchasing Power Parities (PPP) Conversion Factor, Local Currency Unit to International Dollar. The Official United Nations Site for the MDG Indicators. http://unstats.un.org/unsd/mdg/SeriesDetail.aspx?srid=699 Updated July 2013. Date accessed: June 2013.

27 UN. National Accounts Main Aggregates Database. http://unstats.un.org/unsd/snaama/Introduction.asp Updated December 2013. Date accessed: June 2013.

28 UN. UN Data: Exchange Rates. http://data.un.org/Data.aspx?d=IFS\&f=SeriesCode\%3A Date last updated: May 14, 2010. Date accessed: June 2013.

29 Ayé R, Wyss K, Abdualimova $\mathrm{H}$, et al. Factors determining household expenditure for tuberculosis and coping strategies in Tajikistan. Trop Med Int Health 2011; 16: 307-313.

30 Muniyandi M, Ramachandran R, Balasubramanian R. Costs to patients with tuberculosis treated under DOTS programme. Indian J Tuberc 2005; 52: 188-196.

31 Rajeswari R, Balasubramanian R, Muniyandi M, et al. Socio-economic impact of tuberculosis on patients and family in India. Int J Tuberc Lung Dis 1999; 3: 869-877.

32 Karki DK, Mirzoev TN, Green AT, et al. Costs of a successful public-private partnership for TB control in an urbansetting in Nepal. BMC Public Health 2007; 7: 84.

33 Xu B, Dong HJ, Zhao Q, et al. DOTS in China - removing barriers or moving barriers? Health Policy Plan 2006; 21: 365-372.

34 Kemp JR, Mann G, Simwaka BN, et al. Can Malawi's poor afford free tuberculosis services? Patient and household costs associated with a tuberculosis diagnosis in Lilongwe. Bull World Health Organ 2007; 85: 580-585.

35 Needham DM, Godfrey-Faussett P, Foster SD. Barriers to tuberculosis control in urban Zambia: the economic impact and burden on patients prior to diagnosis. Int J Tuberc Lung Dis 1998; 2: 811-817.

36 Mesfin MM, Newell JN, Madeley RJ, et al. Cost implications of delays to tuberculosis diagnosis among pulmonary tuberculosis patients in Ethiopia. BMC Public Health 2010; 10: 173.

37 Jacquet V, Morose W, Schwartzman K, et al. Impact of DOTS expansion on tuberculosis related outcomes and costs in Haiti. BMC Public Health 2006; 6: 209.

38 Lönnroth K, Aung T, Maung W, et al. Social franchising of TB care through private GPs in Myanmar: an assessment of treatment results, access, equity and financial protection. Health Policy Plan 2007; 22: $156-166$.

39 Gibson N, Boillot F, Jalloh H. The cost of tuberculosis to patients in Sierra Leone's war zone. Int J Tuberc Lung Dis 1998; 2: 726-731.

40 Kamolratanakul P, Sawert H, Kongsin S, et al. Economic impact of tuberculosis at the household level. Int J Tuberc Lung Dis 1999; 3: 596-602.

41 Wyss K, Kilima P, Lorenz N. Costs of tuberculosis for households and health care providers in Dar es Salaam, Tanzania. Trop Med Int Health 2001; 6: 60-68.

42 Saunderson PR. An economic evaluation of alternative programme designs for tuberculosis control in rural Uganda. Soc Sci Med 1995; 40: 1203-1212.

43 Sinanovic E, Floyd K, Dudley L, et al. Cost and cost-effectiveness of community-based care for tuberculosis in Cape Town, South Africa. Int J Tuberc Lung Dis 2003; 7: S56-S62.

44 Jackson S, Sleigh AC, Wang GJ, et al. Poverty and the economic effects of TB in rural China. Int J Tuberc Lung Dis 2006; 10: 1104-1110.

45 Pantoja A, Lönnroth K, Lal SS, et al. Economic evaluation of PPM-DOTS in Bangalore, south India. Part II: cost and cost-effectiveness of intensified efforts. Int J Tuberc Lung Dis 2009; 13: 705-712.

46 Ananthakrishnan R, Muniyandi M, Jeyaraj A, et al. Expenditure pattern for TB treatment among patients registered in an urban government DOTS program in Chennai City, South India. Tuberc Res Treat 2012; $2012: 747924$.

47 Othman GQ, Ibrahim MI, Raja'a YA. Costs associated with tuberculosis diagnosis and treatment in Yemen for patients and public health services. East Mediterr Health J 2012; 18: 393-398.

48 Pichenda K, Nakamura K, Morita A, et al. Non-hospital DOT and early diagnosis of tuberculosis reduce costs while achieving treatment success. Int J Tuberc Lung Dis 2012; 16: 828-834.

49 Ayé R, Wyss K, Abdualimova H, et al. Household costs of illness during different phases of tuberculosis treatment in Central Asia: a patient survey in Tajikistan. BMC Public Health 2010; 10: 18.

50 Steffen R, Menzies D, Oxlade O, et al. Patients' costs and cost-effectiveness of tuberculosis treatment in DOTS and non-DOTS facilities in Rio de Janeiro, Brazil. PLoS One 2010; 5: e14014.

51 Rouzier VA, Oxlade O, Verduga R, et al. Patient and family costs associated with tuberculosis, including multidrugresistant tuberculosis, in Ecuador. Int J Tuberc Lung Dis 2010; 14: 1316-1322.

52 John KR, Daley P, Kincler N, et al. Costs incurred by patients with pulmonary tuberculosis in rural India. Int $J$ Tuberc Lung Dis 2009; 13: 1281-1287.

53 Muniyandi M, Ramachandran R, Balasubramanian R, et al. Socio-economic dimensions of tuberculosis control: review of studies over two decades from Tuberculosis Research Center. J Commun Dis 2006; 38: $204-215$.

54 Elamin EI, Ibrahim MI, Sulaiman SA, et al. Cost of illness of tuberculosis in Penang, Malaysia. Pharm World Sci 2008; 30: 281-286

55 Mahendradhata Y, Probandari A, Ahmad RA, et al. The incremental cost-effectiveness of engaging private practitioners to refer tuberculosis suspects to DOTS services in Jogjakarta, Indonesia. Am J Trop Med Hyg 2010; 82: 1131-1139.

56 Sinanovic E, Kumaranayake L. Financing and cost-effectiveness analysis of public-private partnerships: provision of tuberculosis treatment in South Africa. Cost Eff Resour Alloc 2006; 4: 11.

57 Vassall A, Seme A, Compernolle P, et al. Patient costs of accessing collaborative tuberculosis and human immunodeficiency virus interventions in Ethiopia. Int J Tuberc Lung Dis 2010; 14: 604-610.

58 Costa JG, Santos AC, Rodrigues LC, et al. Tuberculosis in Salvador, Brazil: costs to health system and families. Rev Saude Publica 2005; 39: 122-128. 

patients in Sudan. Health Policy 2006; 75: 272-279.

60 Khan MA, Walley JD, Witter SN, et al. Costs and cost-effectiveness of different DOT strategies for the treatment of tuberculosis in Pakistan. Directly Observed Treatment. Health Policy Plan 2002; 17: 178-186.

61 Umar NA, Fordham R, Abubakar I, et al. The indirect cost due to pulmonary tuberculosis in patients receiving treatment in Bauchi State - Nigeria. Cost Eff Resour Alloc 2012; 10: 6.

62 Vassall A, Bagdadi S, Bashour H, et al. Cost-effectiveness of different treatment strategies for tuberculosis in Egypt and Syria. Int J Tuberc Lung Dis 2002; 6: 1083-1090.

63 Meng Q, Li R, Cheng G, et al. Provision and financial burden of TB services in a financially decentralized system: a case study from Shandong, China. Int J Health Plann Manage 2004; 19: Suppl. 1, S45-S62.

64 Zhan S, Wang L, Yin A, et al. Revenue-driven in TB control - three cases in China. Int J Health Plann Manage 2004; 19: Suppl. 1, S63-S78.

65 Ray TK, Sharma N, Singh MM, et al. Economic burden of tuberculosis in patients attending DOT centres in Delhi. J Commun Dis 2005; 37: 93-98.

66 Datiko DG, Lindtjørn B. Cost and cost-effectiveness of smear-positive tuberculosis treatment by Health Extension Workers in Southern Ethiopia: a community randomized trial. PLoS One 2010; 5: e9158.

67 Croft RA, Croft RP. Expenditure and loss of income incurred by tuberculosis patients before reaching effective treatment in Bangladesh. Int J Tuberc Lung Dis 1998; 2: 252-254.

68 Okello D, Floyd K, Adatu F, et al. Cost and cost-effectiveness of community-based care for tuberculosis patients in rural Uganda. Int J Tuberc Lung Dis 2003; 7: S72-S79.

69 Wandwalo E, Robberstad B, Morkve O. Cost and cost-effectiveness of community based and health facility based directly observed treatment of tuberculosis in Dar es Salaam, Tanzania. Cost Eff Resour Alloc 2005; 3: 6.

70 Prado TN, Wada N, Guidoni LM, et al. Cost-effectiveness of community health worker versus home-based guardians for directly observed treatment of tuberculosis in Vitória, Espírito Santo State, Brazil. Cad Saude Publica 2011; 27: 944-952.

71 Mirzoev TN, Baral SC, Karki DK, et al. Community-based DOTS and family member DOTS for TB control in Nepal: costs and cost-effectiveness. Cost Eff Resour Alloc 2008; 6: 20.

72 Jacobs B, Clowes C, Wares F, et al. Cost-effectiveness analysis of the Russian treatment scheme for tuberculosis versus short-course chemotherapy: results from Tomsk, Siberia. Int J Tuberc Lung Dis 2002; 6: 396-405.

73 Mauch V, Woods N, Kirubi B, et al. Assessing access barriers to tuberculosis care with the tool to estimate patients costs: pilot results from two districts in Kenya. BMC Public Health 2011; 11: 43.

74 Laokri S, Drabo MK, Weil O, et al. Patients are paying too much for tuberculosis: a direct cost-burden evaluation in Burkina Faso. PLoS One 2013; 8: e56752.

75 Umar NA, Abubakar I, Fordham R, et al. Direct costs of pulmonary tuberculosis among patients receiving treatment in Bauchi State, Nigeria. Int J Tuberc Lung Dis 2012; 16: 835-840.

76 Aspler A, Menzies D, Oxlade O, et al. Cost of tuberculosis diagnosis and treatment from the patient perspective in Lusaka, Zambia. Int J Tuberc Lung Dis 2008; 12: 928-935.

77 Liu X, Thomson R, Gong Y, et al. How affordable are tuberculosis diagnosis and treatment in rural China? An analysis from community and tuberculosis patient perspectives. Trop Med Int Health 2007; 12: 1464-1471.

78 Rockefeller Foundation, Save the Children, UNICEF, WHO. Universal Health Coverage: A Commitment to Close the Gap. London, Save the Children, 2013.

79 Floyd K, Arora VK, Murthy KJR, et al. Cost and cost-effectiveness of public and private sector collaboration in tuberculosis control: evidence from India. Bull World Health Organ 2006; 84: 437-445.

80 WHO. WHO Guide to Identifying the Economic Consequences of Disease and Injury. Geneva, World Health Organization, 2009.

81 Wagstaff A, Bilger M, Sajaia Z, et al. Health Equity and Financial Protection. Washington, The International Bank for Reconstruction and Development/The World Bank, 2011.

82 Ranson MK. Reduction of catastrophic health care expenditures by a community-based health insurance scheme in Gujarat, India: current experiences and challenges. Bull World Health Organ 2002; 80: 613-621. 